\title{
Investigating the effect of information on mobile banking acceptance barriers
}

\author{
Hossein Vazifehdoost, Shirin Khosrozadeh" and Mahtab Mirzaee far
}

Department of Business Management, Science and Research Branch, Islamic Azad University, Tehran, Iran

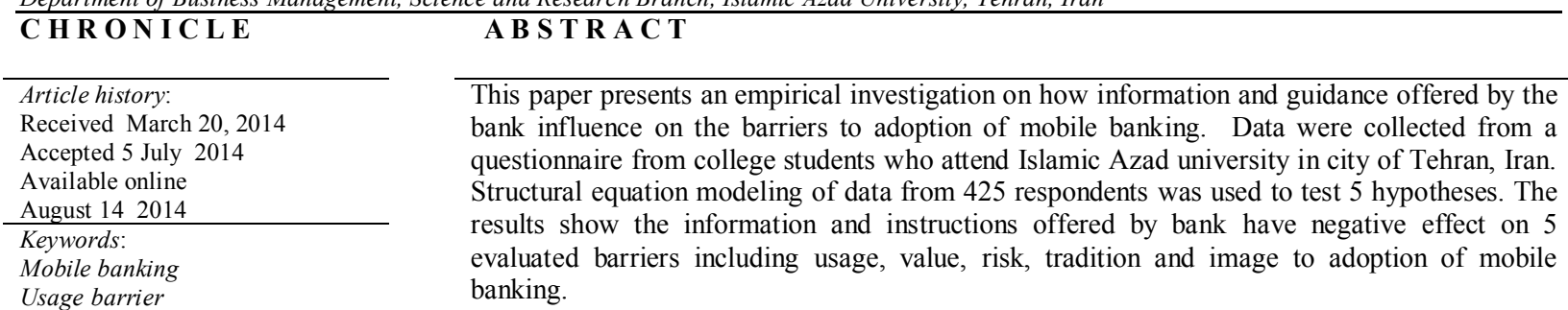

Risk barrier

Tradition barrier

Image barrier

\section{Introduction}

In present competitive world, survival and prosperity of organizations is subject to their abilities in offering an innovative product, from a state of the art commodity to a new service. However, it does not suffice merely to introduce a new product or services for prosperity organization. This is an essential issue in case of service organizations since their products are not intangible for customers and the way their services are received and perceived by customers is important. Nowadays, banking industry struggles with some challenges due to the competitive atmosphere, strict regulations, and customers who are sensitive to prices and are increasingly exposed to new service technologies. Services are offered by various methods and some times, these current services are offered through new channels, which are used by new technologies, such as mobile and internet banking. IT industry and wireless technology have progressed unprecedented during previous decades and have influenced on several industries including banking industry. Wireless technology in aforementioned industry creates new channels such as internet and mobile banking for giving service to customers. Mobile banking is expected to be expanded in near future but from customer's point of view, there are some barriers, which must be overcome. Knowledge-based innovations such as technological innovations mostly require users try to learn how work with them (Saaksjarvi, 2003). Therefore, adapting with

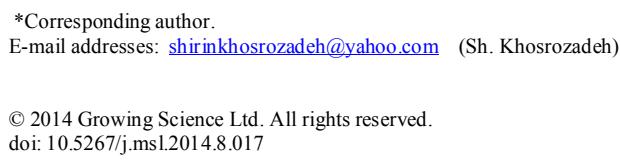


innovation compels consumers to welcome some changes but naturally they resist against these changes. Marketers must be aware that deciding not to purchase is consumer's real right. Recognizing the reasons of this behavior can be very critical to marketers. Presumably, once the consumer overcomes initial sense of resistance against innovation, adaptability will appear (Ram, 1987). Hence, prior to deciding whether to buy or reject a product or service, there is usually some resistance (Kuisma et al., 2007). However, some scholars argue that adaptability and resistance may happen, simultaneously (Ram, 1987). To overcome resistance, the source of resistance must be primarily detected and some actions are needed for decreasing that. Rogers (2010) contends that understanding the reason of changes necessitates establishing relationship. Regarding innovations, it is important that communicability is reached in which product advantages can be conveyed to consumers. The less an innovation can interact with consumers, the more resistance will result (Ram, 1987). The lower the communicability of an innovation, the higher the innovation resistance is likely to be. In previous researches about banking technology, some opponents suffered from lack of information (Kuisma et al. 2007), knowledge (Gerrald et al., 2006), and training (Kuisma et al., 2007). Consequently, the main objective in the present study is to find out how having information about an innovation may influence on consumer's resistance against five barriers including; usage barrier, value barrier, risk barrier, tradition barrier, and image barrier.

\section{Literature Review}

\subsection{Mobile Banking}

Many service providers invest hugely in wireless technology and taking advantage of its opportunities. Offering mobile services with value added to customer help greatly in achieving a competitive advantage on the market. Electronic banking or financial services through electronic devices such as Internet and mobile considerably reduces expenses, increases comfort ability for customers, and changes the way of banks' operations. Two examples of electronic banking inter alias, are development of PDA and online telephones, which enable banking services by mobile equipment. Mobile banking equals implementing financial services through electronic methods. As a matter of fact, it is a bank service that customer can access by using mobile communication techniques of cell phone (Pousttchi \& Schurig, 2004).

\subsection{Mobile Banking Barriers}

Nowadays, bank services provide clients with the possibility to get informed of their remaining balance amount, the last three turnovers bill, ATM accounts list, exchange rate and they can transfer money, check inquiry, pay their bills, and buy SIM card charge. Though Internet banking innovation has spread widely in various countries and studies demonstrate consumers' satisfaction (Pikkarainen et al., 2006), undoubtedly some consumers are not yet inclined to utilize or accept mobile banking services (Laukkanen \& Kiniemi, 2010). Ram \& Sheth (1989) developed a theoretical framework for examining clients' resistance at two levels of functional and psychological levels and the framework has been referred to by many scholars. Besides, functional barriers can be divided into three groups' viz. usage barrier, value barrier, and risk barrier. On the other hand, psychological barriers are divided into two groups i.e. tradition barrier and image barrier. This framework was applied in some previous studies regarding banking technology (Fain \& Robert, 1997; Laukkanen et al., 2009, Cruz et al., 2009; Laukkanen \& Kiviniemi, 2010). This framework was found suitable for present research, too. The aforementioned functional and psychological barriers are explained as follow;

\subsubsection{Usage Barrier}

This barrier refers to functional capacity of an innovation and it occurs when an innovation does not comply with current trends, customs, or habits. Rogers describes it as how difficult one finds recognition and usage of an innovation (Rogers, 2010). For instance, regarding mobile banking, the small size of mobile phone including its small screen and elegant keyboard make using and repairing 
them difficult. In fact, mobile banking system limitations such as small screen, elegant keyboard, and slow transaction pace are accounted for its failure compared with Internet bank (Lee \& Chung, 2009).

\subsubsection{Value Barrier}

It implies the function and monetary value of an innovation in comparison with its alternatives (Ram \& Sheth, 1989). According to Brown et al. (2003), the higher the perceived advantages of mobile banking is, the mobile banking will be more likely accepted.

\subsubsection{Risk Barrier}

It refers to the risk that consumers perceive in using of a new technology. Researchers believe risk is mostly the outcome of consumer's perception rather than the features of a product and marketers must keep this fact in mind (Fain \& Roberts, 1997). It is asserted that some customers are afraid of using their cell phones for doing bank affairs and getting in to trouble (Laukkanen \& Lauronrn, 2005). It is also probable that mobile phone has some limitations for computation, memory capacity, and battery life and consequently limits mobile services in work place (Siau \& Shen, 2003).

\subsubsection{Tradition Barrier}

Functional and technical problems do not clearly and completely justify resistance against innovation. It is stated that low satisfaction or dissatisfaction with electronic financial services is not associated with technology but to personality type (Srijumpa et al., 2002). Tradition barrier seems when an innovation is in contrast with values, current norms and previous experiences (Ram \& Sheth, 1989). When one person conceives on line banking quite different from common way of paying bills, he/she will feel tradition barrier (Fein \& Roberts, 1997). This barrier targets those customers who would rather communicate directly with bank clerks than applying new online technologies.

\subsubsection{Image Barrier}

Image barrier denotes a general image of mobile banking services. Researchers acknowledged image barrier of mobile banking results from common negative image of difficult in using computer in general and Internet specifically (Fain \& Robert, 1997). Nowadays, this is true about bank customers, too. Therefore, some customers conceive technology more difficult than their abilities and accordingly grow a negative image of the services relevant to mobile banking (Laukkanen et al., 2009). It is noted that information, guidance, and assistance by a bank leaves negative effect on image barrier (Laukkanen \& Kiviniemi, 2010).

\section{Research model}

Fig. 1 demonstrates the proposed study of this paper.

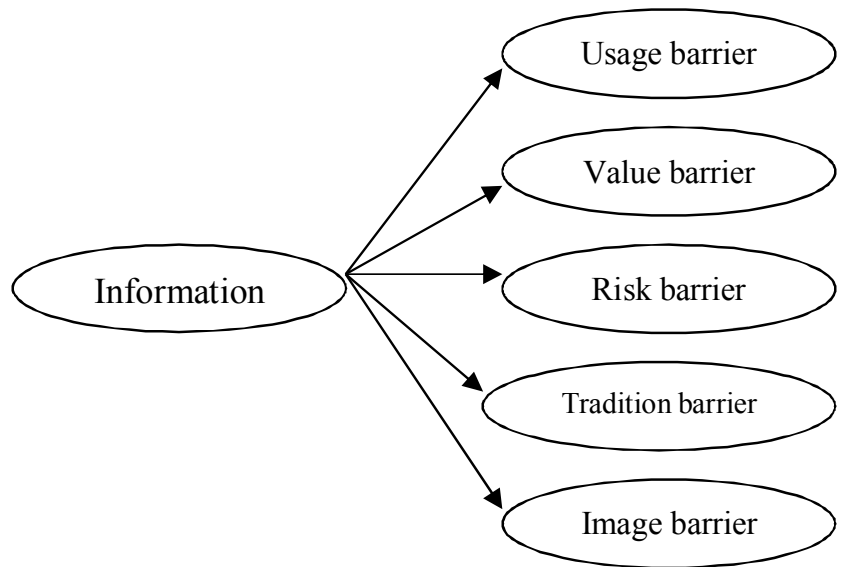

Fig. 1. The proposed study (Laukkanen \& Kiviniemi, 2010) 
According to Fig. 1, the following hypotheses are proposed,

Hypothesis 1: Information and guidance offered by a bank have negative impact on usage barrier. Hypothesis 2: Information and guidance offered by a bank have negative impact on value barrier. Hypothesis 3: Information and guidance offered by a bank have negative impact on risk barrier. Hypothesis 4: Information and guidance offered by a bank have negative impact on tradition barrier. Hypothesis 5: Information and guidance offered by a bank have negative impact on image barrier.

\section{Proposed Design}

The present research is of descriptive, correlation, and survey type and it is categorized as applied research. Sample target includes Azad University students of Science and Research branch in Tehran. Data gathering was done through questionnaire and it lasted for two months from March to April 2014. The research sought to find the impact of information on mobile banking acceptance barriers. University students were chosen as statistical population on account of their greater involvement with mobile banking services, educational level, income, status, social interaction, familiarity, compulsion, and interest in new technologies for online paying (at least paying university tuition).

\subsection{Sampling Method and Defining Sample Size}

Stratified sampling proportional to sample size and systematic random sampling were applied. Sample size was defined 384 based on Krejcie and Morgan table. Once sample size was defined, 450 questionnaires were distributed, 425 of which were applicable.

\subsection{Data Gathering Methods}

Librarian and field methods were used for data gathering as follow; using online documents for review of literature and questionnaire, which was the main tool. The applied questionnaire was standard which was back translated. This questionnaire consisted of two general and demographic parts and included 19 questions evaluated 6 dependent variables including; a- usage barrier, questions 1 to 5 extracted from Kuisma et al. (2007), Laukkanen (2007), Laukkanen and Lauronen (2005), Lee and Chung (2009); b- Value barrier, questions 6 to 8, based on Brown et al. (2003), Laukanen and Lauronen (2005), and Luarn and Lin (2005); c- Risk barrier, questions 9 to 24, based on Brown et al. (2003), Koeisma et al. (2007), Laukkanen (2007b), Laukanen and Lauronen (2005), Lee et al. (2003), Luarn and Lin (2005), and Poon (2008); d- Tradition barrier, questions 13 to 14, based on Fain and Roberts (1997), Gerrard et al. (2006), Marr and Prendergast (1993), Mattila et al. (2003), Srijumpa et al. (2002, 2007); e- image barrier, questions 15 to 16, extracted from Fain and Roberts (1997), Koeisma et al. (2007). Finally, information variable was measured by questions 18 to 19 based on Gerrard et al. (2006), Koeisma et al. (2007), and Mattila et al. (2003). In addition, the five point Likert scale was applied. The general rating of research questions was as; quite agree, agree no idea, disagree, and quite disagree.

\subsubsection{The Validity of Research Measurement Tools}

\subsubsection{The Questionnaire Face Validity}

Respondents were inquired in pre-test whether they find questions clear enough or not. Their opinions were applied for revising questionnaire and finally the face validity of questionnaire was approved by respondents.

\subsubsection{Content Validity}

The utilized questionnaire is internationally standard and approved by marketing experts and researchers throughout the world. On the other hand, marketing specialists' opinions were also used for localizing. Therefore, the questionnaire showed suitable content validity. The value of Alpha 
coefficient for all constructs is higher than 0.7 ; therefore, the validity of questionnaire is ratified. The results are represented in Table 2 .

\section{Results}

Data were analyzed both descriptively (frequency, percentage, mean, and standard deviation) and inferentially. General demographic features were analyzed descriptively but the construct validity was measured inferentially by confirmatory factor analysis. Besides, research hypotheses were tested by structural equation modeling. Computations were done by SPSS and Lisrel software. To describe general demographic features, descriptive statistic indexes were applied. The frequency of respondents based on sex and age is investigated. Sex; 215 persons i.e. $50.06 \%$ of respondents were male and 210 persons were female. Age: 149 respondents were below 25 years old and they had the highest frequency. 142 respondents were between 26 to 33 years old and 134 persons were over 34 years old.

\subsection{Hypotheses Testing}

To this end, initially the data normality test was done. Thereafter, confirmatory factor analysis was done over the questionnaire. Finally, the model relevant to research hypotheses was implemented.

\subsection{Data Normality Test}

The data normality test at 5\% significance level has been performed by Kolmogorov Smirnov technique and Table 1 demonstrates the results of our survey. Note that the hull hypothesis assumes that all data are normally distributed.

\section{Table 1}

The results of Kolmogorov Smirnov for data normality test

\begin{tabular}{lcccccc}
\hline Barrier & Usage & Value & Risk & Tradition & Image & Information \\
\hline Sample size & 425 & 425 & 425 & 425 & 425 & 425 \\
Average & 4.262 & 4.071 & 3.612 & 4.046 & 3.898 & 3.107 \\
Kolmogorov Smirnov & 2.853 & 3.614 & 3.504 & 4.308 & 5.102 & 2.098 \\
p-value & 0.708 & 0.143 & 0.325 & 0.075 & 0.244 & 0.995 \\
\hline
\end{tabular}

In all cases, significance value was bigger than 0.05 . Therefore, there is no reason to reject the hypothesis. In other words, data distribution is normal. Consequently, parametric and factor analysis tests can be used.

\subsection{Confirmatory Factor Analysis}

To examine the construct validity and precision of chosen indicators for measuring constructs, confirmatory factor analysis is applied. The summary of confirmatory factor analysis results for measuring mobile banking barriers are indicated in Table 2. The standard factor load for measuring the strength of relationship between each factor (latent variable) and observable variables (questionnaire items), was bigger than 0.3 in all cases. Hence, the factorial structure of mobile banking barriers is approved. Once the standard factorial load was computed, significance test must be done. According to the results of the factorial load of $t$, measurement index of each dimension at $5 \%$ significance level is bigger than 1.96. Thus, the observed results are significant. The findings are indicated in Table 2. Confirmatory factorial analysis of mobile banking barrier measurement is saturated in three stages. Finally, several goodness of fit indexes are used. One of the common indexes accounting for free parameters in estimation of goodness of fit indexes is the normalized chisquare which is the result of dividing chi-square to degree of freedom of the model. If this value is between 1 to 5 , then $\chi^{2} / d f=367.04 / 94=3.904$. The root mean square error of approximation (RMSEA) equals 0.033 which is smaller than 0.5 . The normalized chi-square is estimated is 3.904 . Therefore, the structural model enjoys high goodness of fit. 
Table 2

Factor loading result

\begin{tabular}{|c|c|c|c|c|c|c|}
\hline Usage barrier & Q1 & $\mathrm{Q} 2$ & Q3 & $\mathrm{Q} 4$ & Q5 & Cronbach $\alpha$ \\
\hline Standard factor loading & 0.47 & 0.50 & 0.29 & 0.59 & 0.77 & 0.726 \\
\hline t-student & 9.08 & 9.83 & 5.37 & 11.57 & 16.06 & \\
\hline Value barrier & Q6 & Q7 & Q8 & & & Cronbach $\alpha$ \\
\hline Standard factor loading & 0.38 & 0.84 & 0.43 & & & 0.784 \\
\hline t-student & 7.45 & 16.82 & 8.52 & & & \\
\hline Risk barrier & Q9 & Q10 & Q11 & Q12 & & Cronbach $\alpha$ \\
\hline Standard factor loading & 0.74 & 0.71 & 0.77 & 0.72 & & 0.846 \\
\hline t-student & 16.66 & 15.82 & 17.54 & 15.97 & & \\
\hline Tradition barrier & Q13 & Q14 & & & & Cronbach $\alpha$ \\
\hline Standard factor loading & 0.88 & 0.62 & & & & 0.755 \\
\hline t-student & 20.57 & 13.61 & & & & \\
\hline Image barrier & Q15 & Q16 & & & & Cronbach $\alpha$ \\
\hline Standard factor loading & 0.91 & 0.91 & & & & 0.764 \\
\hline t-student & 23.63 & 23.95 & & & & \\
\hline Information & Q17 & Q18 & Q19 & & & Cronbach $\alpha$ \\
\hline Standard factor loading & 0.63 & 0.68 & 0.58 & & & 0.732 \\
\hline t-student & 10.67 & 11.22 & 10.12 & & & \\
\hline
\end{tabular}

Confirmatory factorial analysis measures the role of information in two saturated stages. The goodness of fit of RMSEA equals 0.036 , which is smaller than 0.05 . The normalized chi-square is also computed 1.47. Hence, the structural model has high goodness of fit. Table 2 demonstrates the results of confirmatory factorial analysis of the scale measuring mobile banking barriers and the role of information. Once the factorial structure of research constructs (the questionnaire measuring the role of information and mobile banking barriers), was confirmed, structural equations were applied for investigating the relationship between constructs. The outcomes of model's data significance test are represented in Fig. 2. Based on computation outcomes; we make the following conclusions.

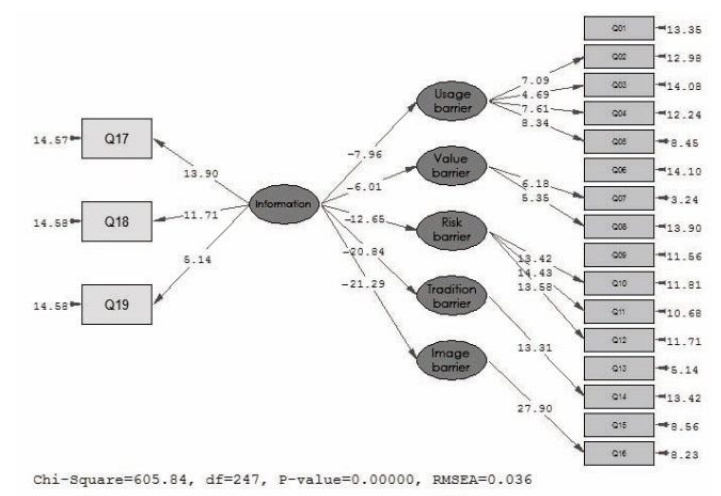

Fig. 2. The results of t-values of the estimated path coefficients

Hypothesis 1: The path coefficient of information impact on usage barrier equals -0.71 . $t$ value is 7.96, which means null hypothesis is rejected. Hence, information has significantly negative effect on mobile banking usage barrier.

Hypothesis 2: The path coefficient of information impact on value barrier equals -0.32 . $t$ value is 6.01. It demonstrates that null hypothesis is rejected. Therefore, information has significantly negative effect on mobile banking value barrier.

Hypothesis 3: The path coefficient of information impact on risk barrier equals -0.75 . $t$ value is 12.65 , which means that null hypothesis was rejected. Thus, information has significantly negative effect on mobile banking risk barrier.

Hypothesis 4: The path coefficient of information impact on tradition barrier equals $-0.45 . \mathrm{t}$ value is 20.84 , which indicates that null hypothesis was rejected. Thus, information has significantly negative effect on mobile banking tradition barrier. 
Hypothesis 5: The path coefficient of information impact on image barrier equals $-0.49 . \mathrm{t}$ value is 21.29, which demonstrates null hypothesis was rejected. Therefore, information has significantly negative effect on mobile banking image barrier. Table 3 demonstrates the path coefficient of constructs' impacts and the significance of estimated parameters (hypothesis testing). The results of the goodness of fit indexes of relevant model are summarized in Table 4. As fitness indicators show, the present research data fits well with factorial structure and theoretical framework of research. It demonstrates the validity of research findings. Therefore, research hypothesis test has high precision.

Table 3

Hypotheses test results

\begin{tabular}{llrcc}
\hline hypotheses & effects of information on barriers to adoption of mobile banking & Path coefficients & t-value & The result \\
\hline H-1 & Information role $\rightarrow$ usage barrier & -0.71 & -7.96 & Confirmed \\
H-2 & Information role $\rightarrow$ value barrier & -0.32 & -6.01 & Confirmed \\
H-3 & Information role $\rightarrow$ risk barrier & -0.75 & -12.65 & Confirmed \\
H-4 & Information role $\rightarrow$ tradition barrier & -0.45 & -20.84 & Confirmed \\
H-5 & Information role $\rightarrow$ image barrier & -0.49 & -21.29 & Confirmed \\
\hline
\end{tabular}

Table 4

The goodness of fit indexes of structural model

\begin{tabular}{llllllll}
\hline Goodness of fit index & IFI & NNFI & NFI & AGFI & GFI & RMSEA & SRMR \\
\hline Computed values & 0.98 & 0.97 & 0.96 & 0.98 & 0.92 & 0.036 & 0.028 \\
\hline
\end{tabular}

\section{Discussions}

Success in current competitive world will not be achieved unless corporations and productive or service institutes proceed shoulder to shoulder and hand in hand with technological developments. Since accepting new innovations necessitates the communication and relationship between the innovation and customers and as well overcoming barriers against acceptance, researchers decided to investigate the role of information and awareness on five barriers of accepting mobile banking. The present research outcomes indicate that 1- The information and instructions offered by bank have negative impact on usage barrier; 2- The information and instructions offered by bank have negative impact on value barrier; 3 - The information and instructions offered by bank have negative impact on risk barrier; 4- The information and instructions offered by bank have negative impact on tradition barrier; 5- The information and instructions offered by bank have negative impact on image barrier.

Due to infrastructure problems of telecommunication systems in Iran, it would not be expected that mobile banking satisfy customers fully. Therefore, if banks attempt to expand electronic banking, they must keep in mind that electronic banking and particularly mobile banking is influenced by legislation and public fear of financial online transactions. Therefore, banks do not have to focus exclusively on a special technology but they must try to take advantage of various technology benefits. In addition, prior to advertising new service technologies, target groups must be defined. If target groups are young, educated, intelligent, adventurous people who are familiar with new online technologies and are interested in firsthand experience with new services, it is anticipated that these people will turn to loyal users of new bank services by spending less time, money, and energy. In the next phase, emulation and world of mouth endorsement will help to expansion of mobile banking services among friends, families, and generally in the society. In this way, the tradition barrier, which entails face to face communication with bank clerks will be removed in long run. It is also suggested that bank service marketers pay due attention both to the risk clients feel in their relationship with mobile banking and values of taking advantage of such services. Therefore, ideally banks must use commercials via mass media, face to face contact with customers and training techniques. Face to face interaction and training techniques help the risk aversion customers to get familiar both with benefits and convenience of mobile banking services and bank security systems to protect online transactions. Utilizing mass media fosters a positive image of mobile banking services. Last but not 
least, it is suggested that there is the possibility of virtual experience with online services so that customers can test these services prior to real transaction and dominate the risk barrier.

\section{References}

Brown, I., Cajee, Z., Davies, D., \& Stroebel, S. (2003). Cell phone banking: predictors of adoption in South Africa-an exploratory study. International Journal of Information Management, 23(5), 381-394.

Fain, D., \& Roberts, M. L. (1997). Technology vs. consumer behavior: the battle for the financial services customer. Journal of Interactive Marketing, 11(1), 44-54.

Gerrard, P., Cunningham, J. B., \& Devlin, J. F. (2006). Why consumers are not using internet banking: a qualitative study. Journal of Services Marketing, 20(3), 160-168.

Kuisma, T., Laukkanen, T., \& Hiltunen, M. (2007). Mapping the reasons for resistance to Internet banking: A means-end approach. International Journal of Information Management, 27(2), 75-85.

Laukkanen, T., \& Kiviniemi, V. (2010). The role of information in mobile banking resistance. International Journal of Bank Marketing, 28(5), 372-388.

Laukkanen, T., \& Lauronen, J. (2005). Consumer value creation in mobile banking services. International Journal of Mobile Communications, 3(4), 325-338.

Laukkanen, T., Sinkkonen, S., \& Laukkanen, P. (2009). Communication strategies to overcome functional and psychological resistance to internet banking. International Journal of Information Management, 29(2), 111-118.

Luarn, P., \& Lin, H. H. (2005). Toward an understanding of the behavioral intention to use mobile banking. Computers in Human Behavior, 21(6), 873-891.

Lee, K. C., \& Chung, N. (2009). Understanding factors affecting trust in and satisfaction with mobile banking in Korea: A modified DeLone and McLean's model perspective. Interacting with computers, 21(5), 385-392.

Marr, N. E., \& Prendergast, G. P. (1993). Consumer adoption of self-service technologies in retail banking: is expert opinion supported by consumer research?. International Journal of Bank Marketing, 11(1), 3-10.

Mattila, M., Karjaluoto, H., \& Pento, T. (2003). Internet banking adoption among mature customers: early majority or laggards?. Journal of Services Marketing,17(5), 514-528.

Pikkarainen, K., Pikkarainen, T., Karjaluoto, H., \& Pahnila, S. (2006). The measurement of end-user computing satisfaction of online banking services: empirical evidence from Finland. International Journal of Bank Marketing, 24(3), 158-172.

Poon, W. C. (2007). Users' adoption of e-banking services: the Malaysian perspective. Journal of Business \& Industrial Marketing, 23(1), 59-69.

Pousttchi, K., \& Schurig, M. (2004, January). Assessment of today's mobile banking applications from the view of customer requirements. In System Sciences, 2004. Proceedings of the 37th Annual Hawaii International Conference on (pp. 10-pp). IEEE.

Ram, S. (1987). A model of innovation resistance. Advances in consumer research, 14(1), 208-212.

Ram, S. (1989). Successful Innovation Using Strategies to Reduce Consumer Resistance An Empirical Test. Journal of Product Innovation Management, 6(1), 20-34.

Ram, S., \& Sheth, J. N. (1989). Consumer resistance to innovations: the marketing problem and its solutions. Journal of Consumer Marketing, 6(2), 5-14.

Rogers, E. M. (2010). Diffusion of innovations. Simon and Schuster.

Saaksjarvi, M. (2003). Consumer adoption of technological innovations.European Journal of Innovation Management, 6(2), 90-100.

Siau, K., \& Shen, Z. (2003). Mobile communications and mobile services.International Journal of Mobile Communications, 1(1), 3-14.

Srijumpa, R., Speece, M., \& Paul, H. (2002). Satisfaction drivers for Internet service technology among stock brokerage customers in Thailand. Journal of Financial Services Marketing, 6(3), 240-253. 